\title{
METROLOGICAL NEEDS FOR MONITORING AQUATIC ENVIRONMENTS: FROM THE DEMONSTRATION OF METROLOGICAL TRACEABILITY TO THE DECISION MAKING PROCESS
}

\author{
Sophie Lardy-Fontan ${ }^{1}$, Nathalie Guigues ${ }^{1}$, Béatrice Lalere ${ }^{1}$ and Sophie Vaslin-Reimann ${ }^{1}$ \\ ${ }^{1}$ LNE, DMSI, Pôle Chimie Biologie 1 rue Gaston Boissier 75724 PARIS Cedex 15
}

\begin{abstract}
In Europe, the implementation of the Water Framework Directive WFD, in 2001, marks a strong standpoint. In addition to its objectives of a return to good chemical and good ecological status by the year 2015, it fixes the achievement of trends over space and time. The new requirements that arise from the WFD put considerable financial pressure on water management authorities. Because the overall decision-making process relies most of the time on acquired data, it puts considerable pressures on the display of high quality biological as well as chemical environmental measurements. However, performing measurements implies that i) the demonstration of their metrological traceability ii) the evidence of their achievement thanks to accurate and sensitive analytical methods and iii) their statement with a reliable estimate of expanded uncertainty is thoroughly addressed. Moreover, the measurement representativeness, especially in highly dynamic environment, is of prime interest in a context where comparability over space and time is needed. As a consequence, considerable challenges are dwelt on metrologists with great emphasis on parameters that are under regulation. This paper will discuss a panorama of the unavoidable metrological questions that have to be addressed: from the definition of the measurand to the final estimation of uncertainty; from the initial performances demonstration of methods to the final demonstration of mastery and capabilities through inter comparison laboratories and reference materials. A focus will be made on upcoming alternative monitoring approaches that are seldom addressed from a metrological point of view.
\end{abstract}

\section{1-Context}

As water is a worldwide-recognized valuable good, for more than fifty years, it has been exponentially scrutinized. Therefore, it may be stated that a widespread contamination of environment by hundreds to thousands various chemicals, physicals and biologicals pressures exists.

\subsection{Water Framework Directive}

The WFD (2000/60/EC) [1], in addition to its objectives of a return to good chemical and good ecological status by the year 2015, fixes the achievement of trends over space and time. The WFD encourages implementing 3 different kinds of monitoring that are complementary:

- surveillance monitoring to check the impact assessment procedure of the WFD, to design future monitoring programs, to assess long-term changes in natural conditions and due to widespread anthropogenic activity; - operational monitoring to establish the status of waterbody identified as being at risk and assess any changes in status resulting from management measures; - investigative monitoring to ascertain the cause of exceedances and to check the magnitude and impacts of accidental pollution.

\subsection{Marine Strategy Framework Directive}

The Marine Strategy Framework Directive (Directive 2008/56/EC [2]), establishing a framework for community action in the field of marine environmental policy, aims at protecting more effectively the marine environment across Europe by achieving good environmental status by 2020 and protecting the resource supporting marine-related economic and social activities. Through the decision of September, 1st 2010, the commission established the criteria and methodological standards on good environmental status of marine waters, stressing that "The concentration of contaminants in the marine environment and their effects need to be assessed taking into account the impacts and threats to the ecosystem".

Because their overall decision-making process are based on measurement data, member states have to ensure that they are fit for purpose or in other words that they meet the quality requirements needed to make a decision with a stated certainty (as stated by [3]). Several issues have then to be addressed: metrological traceability, representativeness, comparability, accuracy with a stated level of uncertainty (Figure 1).

\footnotetext{
${ }^{a}$ Corresponding author: author@email.org
} 


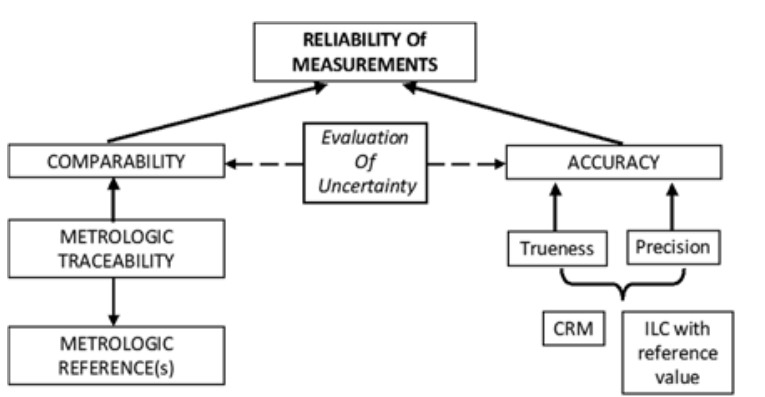

Figure 1: Basics that sustain the concept of reliable environmental chemical measurements

\section{Metrological challenges for qualitative and quantitative measurements of organic pollutants in aquatic ecosystem}

2.1. Why do we need primary calibrators: an illustration with nonylphenols.

Alkylphenols, eg nonylphenols NP, and alkylphenolspolyethoxylates, eg nonylphenols polyethoxylates NPE, are mass-produced chemical compounds. A growing interest in their occurrence and fate in the environment, since the 90's, has led to hundreds of publications. The industrial NP manufacture process results in a highly complex mixture of isomers: isomers of substitution (ortho, meta, para) and isomers of branched alkyl chains. No less than 550 possible isomers exist, but only 50 to 80 nonylphenols had been found in the field.

The numbers provided by the Chemical Abstracts Service (CAS) are the worldwide-accepted identification for chemical substances. Given the complexity of the selected substances, it has to be very rigorously addressed keeping in mind the regulatory requirements (as summarised in Table 1) especially for NP. CAS 25154-52-3 refers to a mixture of alkylphenols of nonyl group of different isomers of substitution ramification of the linear nonyl group. CAS 84852-15-3 refers to para substituted nonylphenols including any types of branching of the nonyl group. CAS 104-40-5 refers to the linear nonyl isomer in para position, i.e. a seldom well defined molecule.

\begin{tabular}{|c|c|c|}
\hline & \multicolumn{2}{|c|}{ Nonylphenols NP } \\
\hline $\begin{array}{l}\text { Directive } \\
\text { 2000/60/EC [1] }\end{array}$ & $\begin{array}{l}25154-52-3 \\
104-40-5\end{array}$ & $\begin{array}{l}\text { Nonylphenols } \\
\text { 4-(para)-nonylphenol }\end{array}$ \\
\hline \multirow[t]{2}{*}{$\begin{array}{l}\text { Directive } \\
\text { 2008/105/EC [2] }\end{array}$} & $104-40-5$ & $\begin{array}{l}\text { Annex I: EQS } \\
\text { Nonylphenol } \\
\text { nonylphenol) } \\
\text { Unless otherwise } \\
\text { specified, it applies to } \\
\text { the total concentration } \\
\text { of all isomers" } \\
\end{array}$ \\
\hline & $\begin{array}{l}25154-52-3 \\
104-40-5\end{array}$ & \begin{tabular}{|l|} 
Annex II: \\
Nonylphenols \\
4-(para)-nonylphenol
\end{tabular} \\
\hline $\begin{array}{l}\text { Directive } \\
\text { 2013/39/EC [4] }\end{array}$ & $\begin{array}{l}\text { not } \\
\text { applicable }\end{array}$ & $\begin{array}{l}\text { Nonylphenols } \\
\text { Nonylphenol (CAS } \\
\text { 25154-52-3,) including } \\
\text { isomers 4-nonylphenol } \\
\text { (CAS 104-40-5) and 4- } \\
\text { nonylphenol (branched) } \\
\text { (CAS 84852-15-3). }\end{array}$ \\
\hline
\end{tabular}

Table 1: Nonylphenol under the scope of the Water Framework Directive: regulatory considerations
This illustrated that it is of prime interest to clearly specify which isomers are to be quantified and then select the appropriate standards.

\subsection{Description of the case study}

On the basis of information available on certificates of reference materials provided by suppliers for nonylphenols, theoretical calculations were conducted aiming at demonstrating how accuracy of measurement can be affected by the calibration.

5 laboratories involved in the measurement of a given sample were considered; each one operating according to its own internal standard operational protocol.

Lab1, Lab2, Lab3 employed the same analytical standard (same supplier, same batch); for their part, Lab4 and Lab5 employed the same analytical standard (same supplier, same batch) but different from Lab1, Lab2 and Lab3. The two different analytical standards, having the same CAS number, presented a level of purity as stated by their certificates of analysis. Each laboratory used the information of the certificate in a different way when face to the preparation of calibration solution.

Lab1 and Lab4 did not take into account the purity of the standard in the estimate of the concentration.

On the opposite, Lab2 and Lab5 took into account the purity of the standard, as stated by the certificate, in the estimate of the concentration.

Finally, Lab3 took into account the purity of the standard in the estimate of the concentration, by reassessing it for each preparation of a new batch of solutions.

Calibration model were built considering the 5 different cases and was applied for the quantification of a given sample as presented by Figure 2. Laboratories that do not apply correction (Lab1 and Lab4) provided measurements in agreement even though being inaccurate (bias of no less than $8 \%$ by comparison to the "true value"). On the contrary, the Lab 3 that applied the most rigorous methodology, similar as the one in use in national metrology institute NMI, showed measurement that seemed underestimated (a) by comparison to the others although their results are actually the most accurate ones (b).
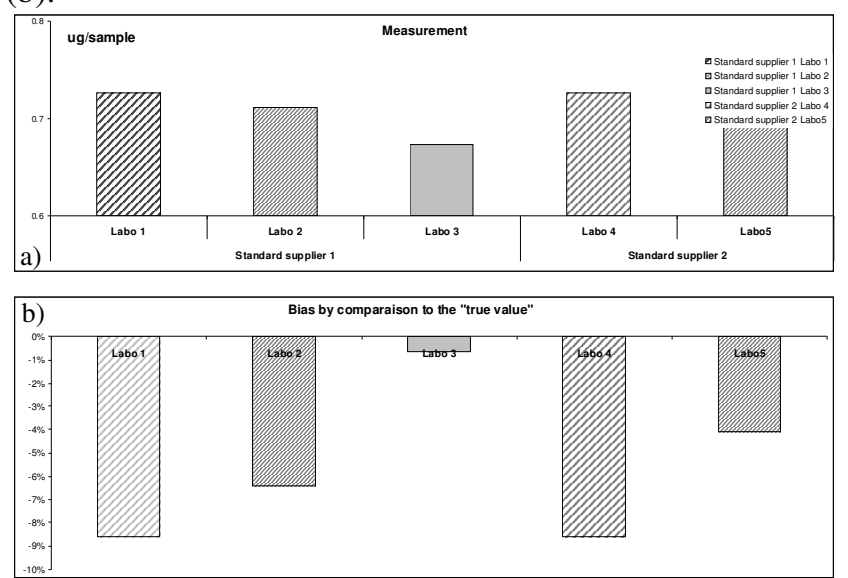

Figure 2: Influence of the consideration of purity of analytical standard on the measurements and the bias. Case study on nonylphenols 
These observations highlight that not taking into account properly the purity of standards used in the calibration process may impair the comparability of measurements. Indeed, the less the purity of the standard is, the more the influence will be, if it is not taken into account in the calibration process.

\section{Metrological challenges for upcoming field measurements in aquatic ecosystems}

\subsection{Monitoring strategies and alternative tools}

Monitoring is defined by IUPAC as a "Continuous or repeated observation, measurement, and evaluation of health and/or environmental or technical data for defined purposes, according to prearranged schedules in space and time, using comparable methods for sensing and data collection" [5] . Until very recently, routine water monitoring was based on periodic spot or grab sampling followed by laboratory analysis (except for the biomonitoring "Mussel watch" approaches that has long been used in marine and coastal water monitoring for years) and the question of representativeness in highly versatile systems still remains.

The European guidance CIS No.19 (2009) [6] on the monitoring of chemical parameters in surface waters mentioned in Chapter 7 that it is highly desirable to introduce other techniques than analysis of grab samples to improve the quality of the assessment of the ecological status. These alternative techniques include passive samplers, continuous measuring devices, portable devices, biological early warning systems etc.

However, several issues have to be addressed to fully understand their potential and how they can be best implemented as presented by Figure 3.
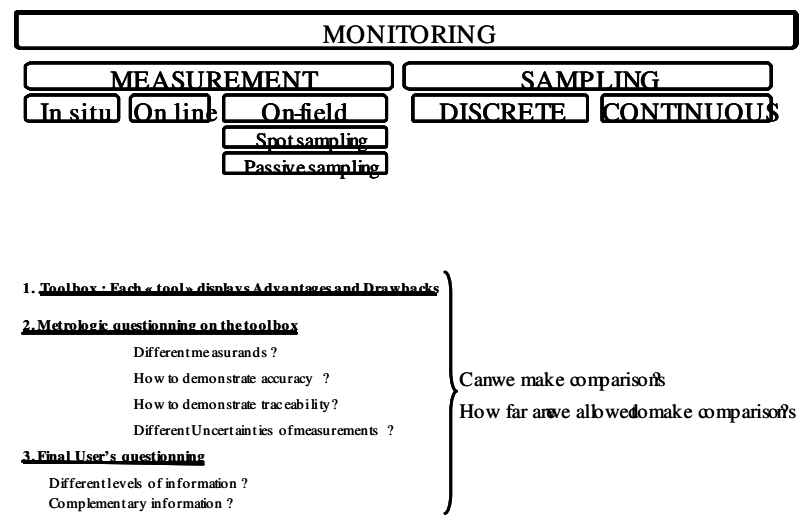

Figure 3: An overview of the complexity of water "monitoring"

\subsection{Are we allowed to make comparisons: the issue of the definition of the measurand}

To illustrate that key point, an example is provided from a research program supported by the French National Radioactive Waste Management Agency aiming at providing a reference comprehensive assessment of the environmental state at the future geological repository. To do so a Long-term Environmental Research Monitoring and Testing System was set up in 2007. A surface water monitoring program has been designed including the assessment of a set of relevant pollutants among which polycyclic aromatic hydrocarbons (the 16 of the EPA agency, except naphthalene). Three different monitoring approaches (Figure 4) have been deployed simultaneously for a two-month period during a pilot case study on the Saulx River in 2011:

- Conventional monitoring strategy consisting of 17 discrete spot samplings

- Passive sampling monitoring strategy using Solid Permeable Membrane devices (SPMD) deployed for given periods of time of 2 to 4 weeks.

- In-situ continuous measurements by means of a fluorescence probe (EnviroFlu-HC).

The comparison is rather difficult as the measurands for each approach have clearly substantial differences. However, valuable information can still be drawn from all three complementary approaches: continuous measurements provide insights in the temporal variability and point source pollution events, whereas passive sampling allows the estimation of time weighted average concentration over a time period, reflecting background variation and/or the identification of compounds at very low level of concentration
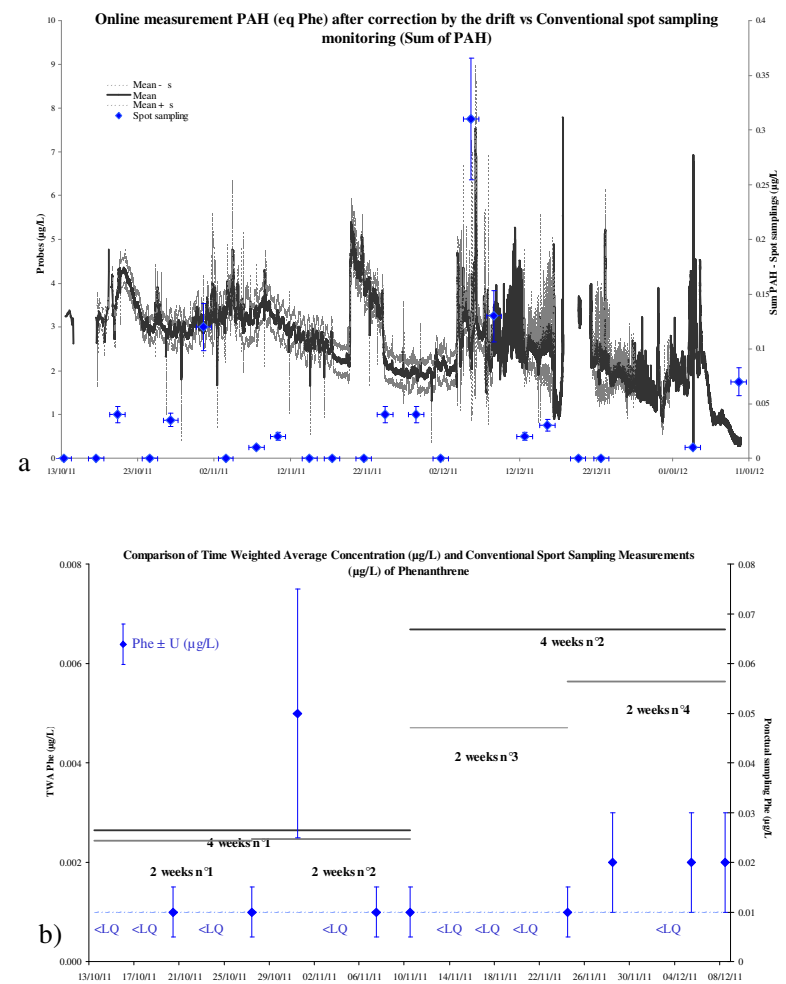

Figure 4: Different monitoring strategies of PAHS in the Saulx River Water (October to December 2012): Comparisons within the concept of better level of information

a) Comparison of online measurement and discrete spot sampling

b) Comparison of passive sampling and discrete spot sampling

\subsection{Accuracy of measurements: How to deal with field calibration of field instruments}

The long-term drift of the EnviroFlu-HC in situ probe was investigated by ANOVA on the slope of the calibration curve calculated from on-site measurements performed on Evian water and standard of phenanthrene at 2 and $12 \mu \mathrm{g} / \mathrm{L}$ at regular interval during 3 months. Results showed that the slope is very stable over time and that there is no significant effect of instrument (5 instruments were tested 
simultaneously) or water temperature. In contrast, looking at the shape of the relationship between the intercept of the calibration curve and time, a drift from October 24, 2011 was identified (Figure 5), the intercept origin is about 0.7 $\mathrm{mg} / \mathrm{L}$ after one week of immersion probes, to no more than $-0.8 \mu \mathrm{g} / \mathrm{L}$ on 10 January 2012 at the end of the test site 3 months. The calibration on the $11^{\text {th }}$ of January was carried out in the laboratory after thoroughly cleaning the probes indicating that the drift observed was probably not due to biofouling and environmental conditions but rather to instrumental drift.

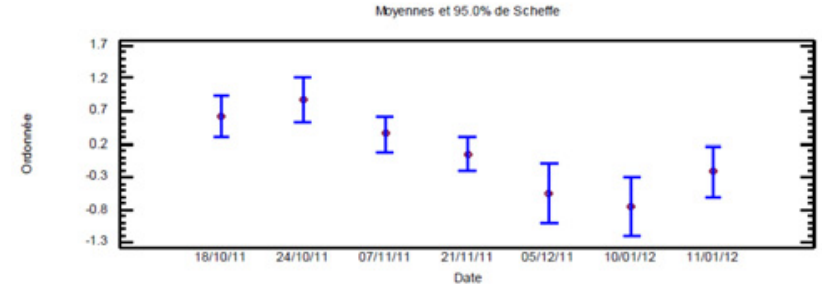

Figure 5: Different monitoring strategies: Comparisons within the concept of better level of information

\subsection{Can we make comparisons: the issue of the estimation of uncertainty}

Uncertainties are still one of the main metrological difficulties within the field of environmental monitoring even with the implementation of ISO/CEN 17025 or other kinds of national or European regulations.

For conventional approach, there is still some misunderstanding between measurement uncertainties that should integrate both sampling uncertainty and laboratory uncertainty. In fact, uncertainty of measurement is usually reduced to the true analytical contribution and that lead to an underestimation of uncertainty and, by way of consequence, affect the ongoing decision making process. For the emerging approaches such as those relying on passive sampling, everything has to be done. The strategies have to be thought and implemented depending on both the type of devices and the kind of targeted analytes. In fact, the level of mastery and knowledge is heterogeneous.

In one hand, passive samplers such as Diffusive Gradients in Thin film DGT for metals or Semi Permeable Membrane SPMD for Polycyclic Aromatic Hydrocarbons (PAH) or PolyChloroBiphenyls (PCB) have been developed, characterized and implemented for a long time for routine monitoring. To follow up their routine implementation and assess their measurements, it is now unavoidable to address the issues of uncertainties of measurements.

In the other hand, for the most recent devices such as Polar Organic Compound Integrative Sampler (POCIS) for pesticides or pharmaceuticals residues, the background and state of knowledge are not sufficient and may impair their large scale implementation for quantitative measurements. Nevertheless, that does mean that it is not necessary to work on uncertainty estimation, indeed we have to be aware that it is very difficult to find tools for some characteristics evaluation. The main ones are accuracy as no CRM exist for passive sampler devices; lack of complementary methodological and metrological information's to enable "exhaustive" uncertainty estimation. Moreover for all of them, some additional mathematical investigations are urgently needed to help environmentalists and analysts deal with, for instance, especially non normality, missing data, very few sets of complete data.

\section{Conclusion and Perspectives}

In this work, we highlight that:

- metrologists in the field of environmental chemistry are urgently asked to address the issues of traceability to ensure more comparable measurements to satisfy these nowadays need. Especially, the metrology community have to address and to find consensus on the concepts of common "metrologic" references.

- an unavoidable work has to be done to go beyond the state of the art concerning the knowledge and mastery of novel monitoring approaches and in consequence to their large scale implementation in the context of European water monitoring sustained by WFD. Metrology needs to address those approaches to improve and make them reliable and to demonstrate their fitness for purpose. Priority actions have to focus on the definition of measurements/measurands that preclude to the uncertainty estimation.

A metrology infrastructure is urgently needed. In Europe, some activities have been initiated under European Metrology Research Program (EMRP call 2013 environment) and will have to be continued in the future European Metrology Programme for Innovation and Research EMPIR. Pluridisciplinary consortia/networks to facilitate end-users, industrials, regulatory bodies, standardization bodies, academic researchers and institutes of metrology synergy and knowledge sharing are also urgently needed.

\section{References}

1 Directive 2000/60/EC of the European Parliament and of the Council of 23 October 2000 establishing a framework for Community action in the field of water policy, http://eurlex.europa.eu/LexUriServ/LexUriServ.do?uri=CELEX:32000L0060:EN:NOT

2 Directive 2008/56/EC of the European parliament and of the council of 17 June 2008 establishing a framework for community action in the field of marine environmental policy (Marine Strategy Framework Directive). http://eur-lex.europa.eu/LexUriServ/LexUriServ.do?uri=OJ:L:2008:164:0019:0040:EN:PDF

3 QA/QC Directive (2009/90/EC), "Commission directive 2009/90/EC of 31 July 2009 laying down, pursuant to Directive 2000/60/EC of the European Parliament and of the Council, technical specifications for chemical analysis and monitoring of water status", http://eurlex.europa.eu/LexUriServ/LexUriServ.do?uri=OJ:L:2009:201:0036:0038:EN:PDF

4 Directive 2013/39/EU of the European parliament and of the council of 12 August 2013 amending Directives 2000/60/EC and 2008/105/EC as regards priority substances in the field of water policy. http://eurlex.europa.eu/LexUriServ/LexUriServ.do?uri=OJ:L:2013:226:0001:0017:EN:PDF

5 IUPAC. Compendium of Chemical Terminology, 2nd ed. (the "Gold Book"). Compiled by A. D. McNaught and A. Wilkinson. Blackwell Scientific Publications, Oxford (1997). XML on-line corrected version: http://goldbook.iupac.org (2006) created by M. Nic, J. Jirat, B. Kosata; updates compiled by A. Jenkins. ISBN 0-9678550-9-8. doi:10.1351/goldbook.

6 European Commission, WFD-CIS Guidance Document No. 19 Guidance on Surface Water Chemical Monitoring under The Water Framework Directive, Office for Official Publications of the European Communities, Luxembourg, 2009, p. 130. (http://circa.europa. eu/Public/irc/env/wfd/library?l=/framework_directive/guidance_documents/guidance_monitorin gpdf/_EN_1.0_\&a=d). 